\title{
DR. PAULA NINA GOERING
}

\section{(March 1947-May 2016)}

\author{
By Elizabeth Lin
}

I first met Paula Goering in 1989 when I came to Canada to work in her Unit at what was then the Clarke Institute of Psychiatry. For me, the most astonishing thing about Paula and the legacy she has left is the breadth and depth of her vision of what mental health care should look like.

As a clinician, she had a deep understanding of the importance of listening to the personal stories of clients and their families about how mental illness affected their lives. As a health services researcher, she also understood the importance of addressing the impersonal aspects of health care and social support (i.e., how they were structured, operated, and funded) as well as the value of providing population- and systemlevel evidence to order to be effective about influencing and changing the system. The vision that she conveyed was of a system which valued, included, and integrated multiple levels of evidence and stories - from the largest system to the individual clients - and used this evidence to improve the care and services being provided. The end goals were not only a better functioning system but, most important, positive and lasting impacts on people's lives.

She had a number of tools to help her achieve this vision. Her professional clinical and research training provided obvious formal skills in diagnosis, treatment, critical thinking, and solid scientific research methods. On the personal side, she was passionate about improving the lives of individuals with mental illness and addictions. She was an extremely effective networker and understood the critical role that sharing knowledge played in creating and sustaining connections. In addition, she had remarkable empathy and patience. Dealing with stakeholders at multiple levels is extremely complex. Many of us watched (in awe) at her kind and patient persistence in dealing with problems long past when we would have quit in frustration. Most importantly, she managed to integrate her training and personal skills without letting one overwhelm the other in the service of the larger objective. The effectiveness and consistency of her vision is clear in all of her professional projects: from the large national Housing First/Chez Soi study, to the establishment of the Ontario-based Evidence Exchange Network (EENet), to the many smaller consultations that she and her Unit did with local and regional government bodies and individual community agencies and hospitals. In addition, in a less public way, she "walked the walk." She mentored many students, staff, and colleagues, and her values of inclusiveness, compassion, and mutual respect guided her working and personal relationships as well as the way she lived her life.

Community mental health, specifically, was seen as an undervalued and comparatively neglected care sector. She was among the many voices noting the irony of the push to deinstitutionalization combined with a lack of community-targeted resources. She also had a long-standing concern about the need for good quality information and evidence from the community sector. She would have welcomed the work described in these two special issues of CJCMH and possibly would have said (to herself in her quiet way), "It's about time." 